\title{
Synthesis and Oxygen Permeability of Polynorbornene with Tosylate Side Chain Group
}

\author{
Armando Pineda Contreras, Mikhail A. Tlenkopatchev, ${ }^{\dagger}$ \\ Takeshi OGAWA, and Tsutomu NAKAGAWA* \\ Instituto de Investigaciones en Materiales, Universidad Nacional Autónoma de México, \\ Apartado Postal 70-360, CU, Coyoacán, México DF 04510, México \\ ${ }^{*}$ Department of Industrial Chemistry, Meiji University, Kawasaki 214-0033, Japan
}

(Received March 16, 2001; Accepted June 26, 2001)

\begin{abstract}
A new oxygen/nitrogen separation membrane based on a polynorbornene with tosylate side chain group was synthesized using well-defined vinylidene ruthenium catalysts. The permeability, separation factor, diffusion and solubility coefficients of a polynorbornene membrane were studied. The introduction of tosylate group into the fivemembered ring of the polynorbornene main chain results in increase of $T_{\mathrm{g}}$ and significant improvement in selectivity for $\mathrm{O}_{2} / \mathrm{N}_{2}$.

KEY WORDS Norbornene with Tosylate Substituent / Metathesis Polymerization / Ruthenium Catalysts / Polynorbornene with Tosylate Side Chain Group / Oxygen Permeability /
\end{abstract}

The separation and recovery of oxygen/nitrogen from air using polymer membranes have gained much attention. ${ }^{1,2}$ For example, oxygen-enriched air can be used for medical applications, for oxidation processes of chemicals, for enhanced fuel combustion, etc. Polynorbornenes have been the subject of investigations for potential uses in packaging and gas separation. ${ }^{3}$ Thus, the permeability and sorption properties of ring-opened polynorbornenes with silicon and fluorine-containing side chain groups were reported. ${ }^{4-6}$ The authors ${ }^{7,8}$ studied the gas transport properties of ring-preserved polynorbornenes prepared via addition polymerization route.

There are many investigations on the preparation of functionalized polymers by ring-opening metathesis polymerization (ROMP) of norbornene derivatives. ${ }^{9}, 10$ The norbornene monomers are attractive due to facile functionalization, high reactivity in ROMP and in the ring-preserving polymerization. ${ }^{11,12}$ The high molecular weight functionalized polynorbornene with good mechanical properties can be obtained by ROMP using appropriate catalysts tolerating functional groups.

The high tolerance of heteroatoms and protic functionalities makes $\mathrm{Ru}$ containing compounds very attractive catalysts for metathesis of the various polar monomers. Early it was demonstrated that simple ruthenium complexes can be activated toward olefin metathesis by addition of diazoesters as carbene source. ${ }^{13}$ The authors ${ }^{14,15}$ used diphenyl cyclopropene and diazoalkanes as carbene source for the preparation of novel alkylidene ruthenium complexes that are highly efficient catalysts for olefin metathesis and tol- erate a large number of polar functional groups.

Recently the efficiency of the new vinylidene ruthenium(II) complexes for ROMP of norbornene derivatives has been reported. ${ }^{16}$

The present study describes the synthesis of polynorbornene with tosylate side chain group via ROMP of 2-(tosylamethyl)norborn-5-ene using accessible ruthenium vinylidene catalysts and characterization of this polynorbornene for oxygen/nitrogen permeability.

\section{EXPERIMENTAL}

\section{Materials}

Polymerization solvents were distilled over calcium hydride. $\mathrm{RuCl}_{2}\left(\mathrm{PR}_{3}\right)_{3}$ and $\mathrm{Cl}_{2}\left(\mathrm{PR}_{3}\right)_{2} \mathrm{Ru}=\mathrm{C}=\mathrm{CH}(t-\mathrm{Bu})$ $\left(\mathrm{R}=\mathrm{PPh}_{3}, \mathrm{PCy}_{3}\right)$ were prepared according to the literature. ${ }^{16,17}$ Other reagents (Aldrich) were used as recieved. 2-(Tosylamethyl)norborn-5-ene (TNB) was prepared as described previously (Scheme 1). ${ }^{12}$

\section{Polymerization of TNB}

The metathesis polymerization of TNB (Scheme 2) and its copolymerization with norbornene $(\mathrm{NB})$ were

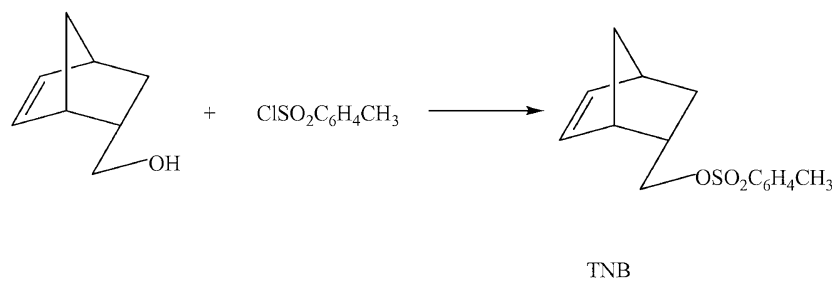

Scheme 1. Synthesis of monomer (TNB). 
Table I. Polymerization of TNB by ruthenium catalysts in chlorobenzene

\begin{tabular}{|c|c|c|c|c|c|c|c|c|}
\hline Entry & Catalyst & $\frac{\text { Mon./Catal. }}{\text { mol. ratio }}$ & $\frac{[\mathrm{M}]_{0}}{\mathrm{~mol} \mathrm{~L}^{-1}}$ & $T /{ }^{\circ} \mathrm{C}$ & $\frac{\text { Time }}{\mathrm{h}}$ & Yield $/ \%{ }^{\mathrm{f}}$ & $M_{\mathrm{n}}^{\mathrm{g}} / 10^{5}$ & $M_{\mathrm{w}} / M_{\mathrm{n}}^{\mathrm{g}}$ \\
\hline 1 & $\overline{\mathrm{A}^{\mathrm{a}}}$ & 100 & 1.0 & 70 & 24 & 48 & 1.2 & 2.21 \\
\hline 2 & $\mathrm{~A}+5 \mathrm{CH} \equiv \mathrm{CPh}^{\mathrm{b}}$ & 100 & 0.8 & 45 & 18 & 72 & 0.9 & 3.25 \\
\hline 3 & $\mathrm{~A}+5 \mathrm{CH} \equiv \mathrm{CPh}$ & 200 & 1.0 & 45 & 24 & 45 & 1.6 & 3.12 \\
\hline 4 & $\mathrm{~A}+5 \mathrm{CH} \equiv \mathrm{CPh}$ & 80 & 1.0 & 60 & 18 & 81 & 0.7 & 3.67 \\
\hline 5 & $\mathrm{~A}+5 \mathrm{CH} \equiv \mathrm{CSi}\left(\mathrm{CH}_{3}\right)_{3}{ }^{\mathrm{b}}$ & 100 & 0.8 & 45 & 24 & 78 & 1.1 & 3.09 \\
\hline 6 & $\mathrm{~A}+5 \mathrm{CH} \equiv \mathrm{CSi}\left(\mathrm{CH}_{3}\right)_{3}$ & 80 & 1.0 & 60 & 18 & 85 & 0.6 & 2.87 \\
\hline 7 & $\mathrm{~B}^{\mathrm{c}}$ & 100 & 0.8 & 45 & 24 & 79 & 1.1 & 2.45 \\
\hline 8 & B & 80 & 1.0 & 45 & 12 & 85 & 1.8 & 2.21 \\
\hline $9^{d}$ & $\mathrm{C}^{\mathrm{e}}$ & 100 & 1.0 & 25 & 48 & 58 & 2.2 & 1.97 \\
\hline $10^{\mathrm{d}}$ & $\mathrm{C}$ & 100 & 1.0 & 40 & 6 & 89 & 3.1 & 2.11 \\
\hline
\end{tabular}

${ }^{\mathrm{a}} \mathrm{A}=\mathrm{RuCl}_{2}\left(\mathrm{PPh}_{3}\right)_{3} .{ }^{\mathrm{b}} \mathrm{Generated}$ in situ. ${ }^{\mathrm{c}} \mathrm{B}=\mathrm{Cl}_{2}\left(\mathrm{PPh}_{3}\right)_{2} \mathrm{Ru}=\mathrm{C}=\mathrm{CH}(t-\mathrm{Bu})$. ${ }^{\mathrm{d}}$ Solvent $\mathrm{CH}_{2} \mathrm{Cl}_{2} \cdot{ }^{\mathrm{e}} \mathrm{C}=\mathrm{Cl}_{2}\left(\mathrm{PCy}_{3}\right)_{2} \mathrm{Ru}=\mathrm{C}=\mathrm{CH}(t-\mathrm{Bu})$. ${ }^{\mathrm{f}}$ Methanol insoluble polymer. ${ }^{\mathrm{g}}$ Determined by GPC in chloroform with polystyrene calibration standards.

Table II. Composition and $T_{\mathrm{g}}$ of copolymers of TNB with NB

\begin{tabular}{|c|c|c|c|c|c|}
\hline \multicolumn{2}{|c|}{ TNB } & \multirow[b]{2}{*}{ Yield $/ \%{ }^{c}$} & \multirow[b]{2}{*}{$M_{\mathrm{n}} / 10^{5}$} & \multirow[b]{2}{*}{$M_{\mathrm{w}} / M_{\mathrm{n}}^{\mathrm{d}}$} & \multirow[b]{2}{*}{$T_{\mathrm{g}} /{ }^{\circ} \mathrm{C}^{\mathrm{e}}$} \\
\hline$\frac{\text { Feed }^{\mathrm{a}}}{\mathrm{mol}^{2}}$ & $\frac{\text { Copolymer }^{\mathrm{b}}}{\mathrm{mol} \%}$ & & & & \\
\hline 0 & & 78 & 3.5 & 2.2 & 38 \\
\hline 30 & 28 & 85 & 2.2 & 2.5 & 58 \\
\hline 50 & 47 & 89 & 2.1 & 2.1 & 63 \\
\hline 70 & 66 & 86 & 1.9 & 1.8 & 74 \\
\hline 100 & & 82 & 2.7 & 2.3 & 95 \\
\hline
\end{tabular}

${ }^{\mathrm{a}}$ Copolymerization was carried out in 1,2-dichloroethane by $\mathrm{Cl}_{2}\left(\mathrm{PCy}_{3}\right)_{2} \mathrm{Ru}=\mathrm{C}=\mathrm{CH}(t-\mathrm{Bu})$ at $40^{\circ} \mathrm{C}$, total concentration of monomers $1 \mathrm{M}$, concentration of catalyst $10 \mathrm{mM}$. ${ }^{\mathrm{b}} \mathrm{Calculated}$ by ${ }^{1} \mathrm{H}$ NMR integration. ${ }^{\mathrm{c}}$ Methanol insoluble polymer after $6 \mathrm{~h}$ of reaction. ${ }^{\mathrm{d}} \mathrm{GPC}$ analysis in chloroform with polystyrene standards. ${ }^{~}$ Reported as inflection point of the second DSC trace at heating rate $10^{\circ} \mathrm{C} \mathrm{min}^{-1}$ in $\mathrm{N}_{2}$.
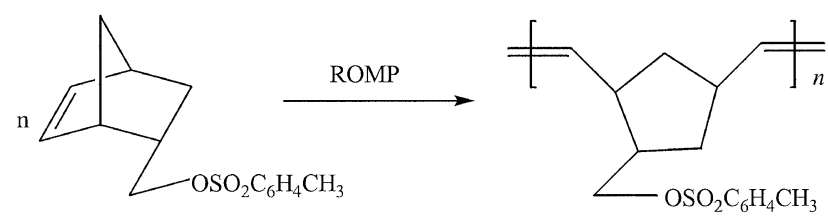

TNB

$$
\text { poly-TNB }
$$

Scheme 2. Synthesis of poly-TNB via ROMP.

carried out using ruthenium catalysts (Table I and II) under dry nitrogen atmosphere. A typical polymerization experiment is as follows: $3 \mathrm{~g}$ TNB were dissolved in $21 \mathrm{~mL} \mathrm{1,2-dichloroethane} \mathrm{under} \mathrm{dry} \mathrm{nitrogen.} 30 \mathrm{mg}$ $\mathrm{Cl}_{2}\left(\mathrm{PCy}_{3}\right)_{2} \mathrm{Ru}=\mathrm{C}=\mathrm{CH}(t-\mathrm{Bu})$ in $\mathrm{CH}_{2} \mathrm{Cl}_{2}$ were added. The reaction mixture was heated at $40^{\circ} \mathrm{C}$ for $6 \mathrm{~h}$. The polymer formed was precipitated into methanol and purified by repricipitation from chloroform into methanol. The polymer was dried in a vacuum oven at $40^{\circ} \mathrm{C}$ for $24 \mathrm{~h}$.

\section{Measurements}

FT-IR-spectra were recorded using a Nikolet $510 \mathrm{p}$ spectrometer. ${ }^{1} \mathrm{H}$ NMR and ${ }^{13} \mathrm{C}$ NMR were taken with TMS as the internal standard using a Varian at 300 and $75.5 \mathrm{MHz}$, respectively. Molecular weight and molec- ular weight distribution of polynorbornene were estimated relative to polystyrene standards using a Varian GPC apparatus with THF solvent. Glass transition temperatures $\left(T_{\mathrm{g}}\right)$ were measured by differential scanning calorimetry method at $0-100^{\circ} \mathrm{C}$. Permeability of polymers was studied using a mass-spectrometric method. The measurements were performed in a setup with Balzers QMG-400 instrument at different temperature $\left(30-60^{\circ} \mathrm{C}\right)$. Gas pressure of $100-400 \mathrm{~mm} \mathrm{Hg}$ over the film. Diffusion coefficients were determined using Daines-Barrer or time-lag method. Solubility coefficients were found using basic permeability equation. Films with thickness $50-100 \mathrm{~mm}$ were obtained by pouring a $2 \%$ toluene or chloroform solutions onto a horizontal cellophane surfaces by slow evaporation of the solvent first at room temperature (ambient conditions) and then in vacuum. The effective gas permeation coefficient was $2-3$ orders. In the case of the norbornene polymers, the it was 2 . For the separation coefficients the order was 2 . The error of gas permeation coefficient is less than $1 \%$. 


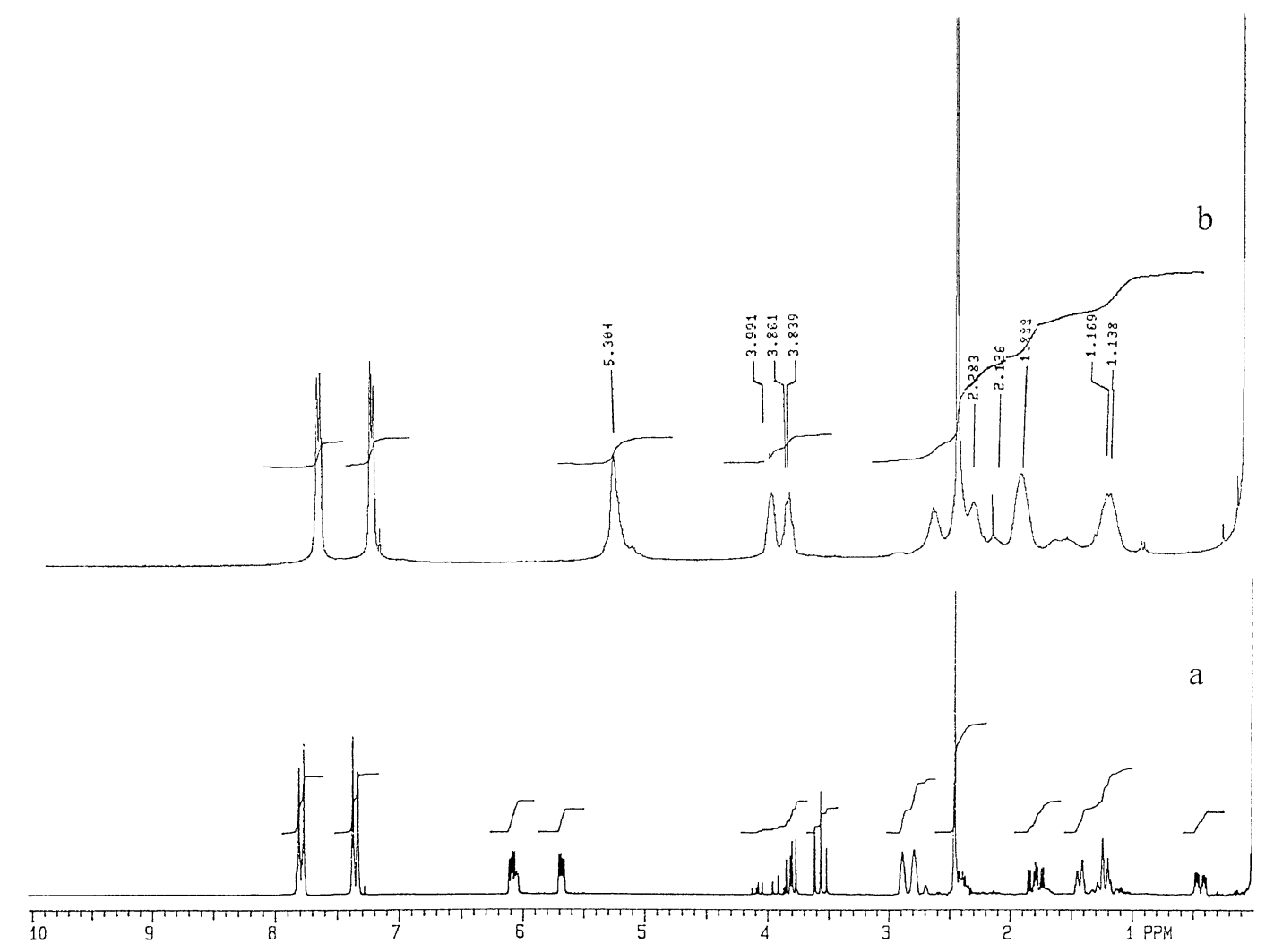

Figure 1. ${ }^{1} \mathrm{H}$ NMR spectra of TNB (a) and its polymer (b) prepared by $\mathrm{Cl}_{2}\left(\mathrm{PCy}_{3}\right)_{2} \mathrm{Ru}=\mathrm{C}=\mathrm{CH}(t-\mathrm{Bu})$ in $\mathrm{CDCl}_{3}$.

\section{RESULTS AND DISCUSSION}

Monomer TNB was polymerized using ruthenium vinylidene catalysts and ruthenium complexes generated in situ from $\mathrm{RuCl}_{2}\left(\mathrm{Ph}_{3}\right)_{3}$ and phenylacetylene (trimethylsilylvinylacetylene) (Scheme 2). Table I summerizes typical results of ROMP of TNB. In situ ruthenium complexes were effective and show comparable with ruthenium vinylidene catalysts activity in ROMP of TNB. Ruthenium vinylidene catalysts (Table I, entr. 7-10) gave polymers with narrower molecular weight distributions (MWD). The polymerization of TNB by ruthenium catalysts proceeds with high yields to produce polymers with the preferential trans configuration of double bonds. It is seen from Table I that polymer yield is sensitive to the monomer/catalyst ratio and increasing this ratio more than 100 leaded to rapid reduction of the polymer yeild. GPC showed that the number average molecular weight $\left(M_{\mathrm{n}}\right)$ and MWD were $0.6-2.2 \times 10^{5}$ and 1.97-3.25, respectively (Table I).

${ }^{1} \mathrm{H}$ NMR spectra of the monomer (a) and polymer (b) prepared by ruthenium vinylidene catalyst are presented in Figure 1. The monomer olefinic signals between 5.65 and 6.1 are replaced by a new signal with a maximum $5.30 \mathrm{ppm}$ corresponding to the linear olefinic protons of the predominant trans double bond of the polymer. ${ }^{10}$ The ${ }^{13} \mathrm{C}$ NMR spectrum (Figure 2) also suggests that the polymer contains predominantly trans double bonds and consists of aromatic peaks at 128$130 \mathrm{ppm}$., four different olefinic carbons of polymer chain from 131.4 to $135.7 \mathrm{ppm}$. corresponding to head to tail and tail to head enchaiments along the chain. ${ }^{10}$ Signals at $74-76 \mathrm{ppm}$. and $20.08 \mathrm{ppm}$. correspond to aliphatic carbons of $\mathrm{CH}_{2} \mathrm{O}$ and $\mathrm{CH}_{3}$ of benzene ring, respectively.

Copolymerization of TNB with NB was carried out by $\mathrm{Cl}_{2}\left(\mathrm{PCy}_{3}\right)_{2} \mathrm{Ru}=\mathrm{C}=\mathrm{CH}(t-\mathrm{Bu})$. Polymers with number average molecular weight $\left(M_{\mathrm{n}}\right)$ between $1.9-2.2 \times$ $10^{5}$ and polydispersities of $1.8-2.5$ were obtained with $30-70 \mathrm{~mol} \%$ of TNB in the feed (Table II). Copolymer compositions were determined by ${ }^{1} \mathrm{H}$ NMR integration and found to be $28-66 \mathrm{~mol} \%$ of TNB, indicating practically the same incorporation of monomers in copolymerization. Structures of copolymers were confirmed by NMR spectroscopy $\left({ }^{1} \mathrm{H}\right.$ and $\left.{ }^{13} \mathrm{C}\right)$. NMR showed the disappearance of monomer olefinic protons and carbons and the appearance of linear olefinic protons at 5.28 and carbons at $131.4-137.9 \mathrm{ppm}$, respectively. Copolymers at all compositions gave only one $T_{\mathrm{g}}$ and these values are between $T_{\mathrm{g}}$ of the two homopolymers. $T_{\mathrm{g}} \mathrm{s}$ of copolymers increased linearly with TNB content.

The effect of the polymer structure on the permeability coefficients for $\mathrm{O}_{2}$ and $\mathrm{N}_{2}$ and $\mathrm{O}_{2} / \mathrm{N}_{2}$ separa- 


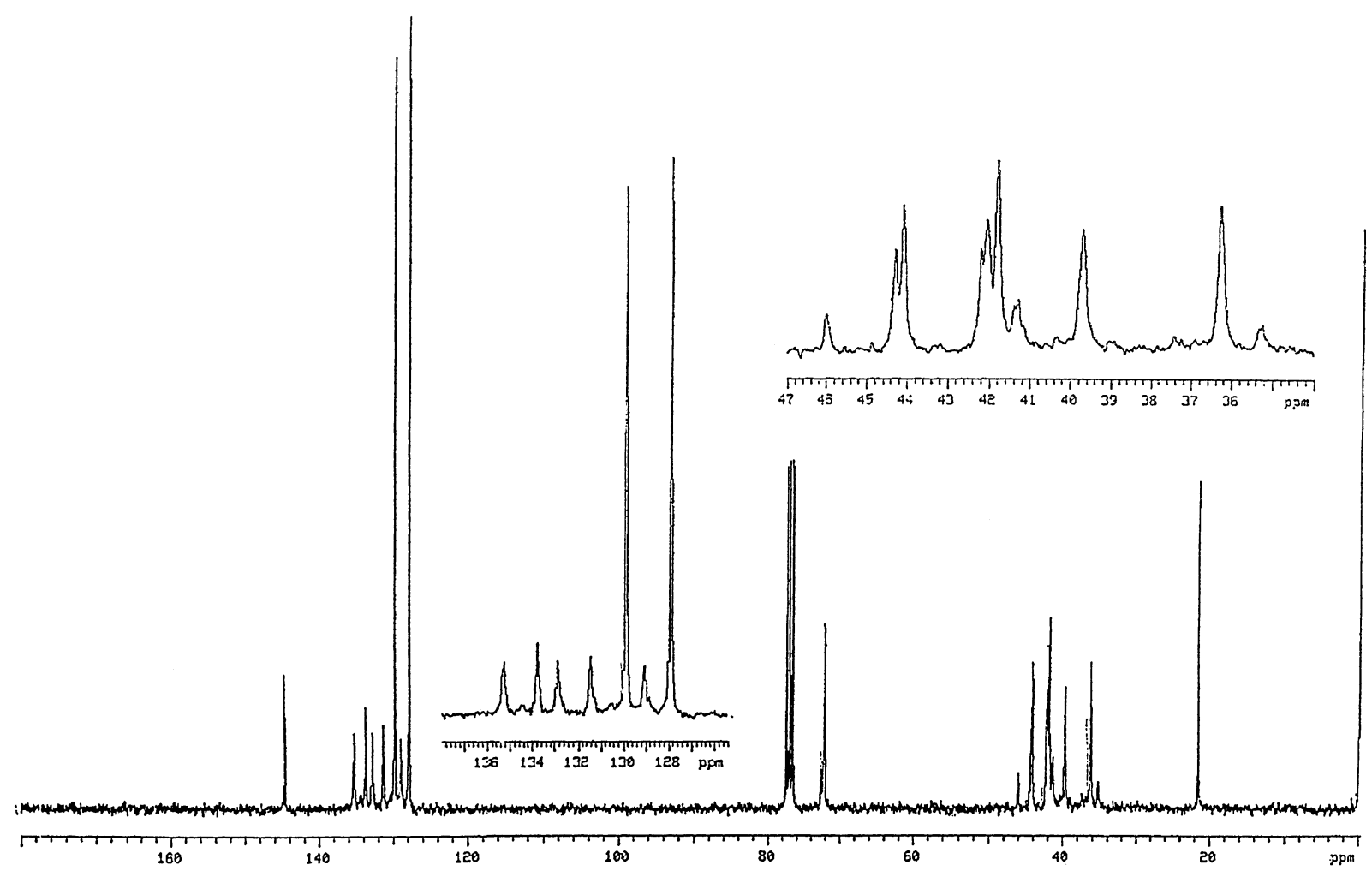

Figure 2. ${ }^{13} \mathrm{C}$ NMR spectrum of poly-TNB prepared by $\mathrm{A}+5 \mathrm{CH} \equiv \mathrm{CPh}$ (entr. 2, Table I) in $\mathrm{CDCl}_{3}$.

Table IV. Permeability of copolymers at different temperature

\begin{tabular}{|c|c|c|c|c|c|c|c|c|}
\hline \multirow{3}{*}{$\frac{\text { NB:NBT }}{\text { mol }}$} & \multicolumn{6}{|c|}{ Barrer $^{\mathrm{a}}$} & & \\
\hline & \multicolumn{2}{|c|}{$30^{\circ} \mathrm{C}$} & \multicolumn{2}{|c|}{$40^{\circ} \mathrm{C}$} & \multicolumn{2}{|c|}{$50^{\circ} \mathrm{C}$} & \multicolumn{2}{|c|}{$60^{\circ} \mathrm{C}$} \\
\hline & $\mathrm{O}_{2}$ & $\mathrm{~N}_{2}$ & $\mathrm{O}_{2}$ & $\mathrm{~N}_{2}$ & $\mathrm{O}_{2}$ & $\mathrm{~N}_{2}$ & $\mathrm{O}_{2}$ & $\mathrm{~N}_{2}$ \\
\hline $30: 70$ & 0.40 & 0.07 & 0.78 & 0.14 & 1.18 & 0.2 & 1.8 & 0.42 \\
\hline $50: 50$ & 0.38 & 0.07 & 0.71 & 0.13 & 1.1 & 0.21 & - & - \\
\hline $70: 30$ & 0.36 & 0.08 & 0.53 & 0.13 & 0.79 & 0.22 & 0.98 & 0.40 \\
\hline
\end{tabular}

${ }^{\mathrm{a}} 1$ Barrer $=10^{-10} \mathrm{~cm}^{3}(\mathrm{STP}) \mathrm{cm} /\left(\mathrm{cm}^{2} \mathrm{~s} \mathrm{cmHg}\right)$.

Table III. Glass transition temperature $\left(T_{\mathrm{g}}\right)$, oxygen/nitrogen permeability and separation factor of poly-TNB and copolymers of TNB with NB

\begin{tabular}{|c|c|c|c|c|}
\hline Membrane & $T_{\mathrm{g}}^{\mathrm{a} /} /{ }^{\circ} \mathrm{C}$ & $\mathrm{O}_{2}$ /Barrer $^{\mathrm{b}}$ & $\mathrm{N}_{2} /$ Barrer $^{\mathrm{b}}$ & $\mathrm{O}_{2} / \mathrm{N}_{2}$ \\
\hline $\mathrm{PNB}^{\mathrm{c}}$ & 31 & 2.8 & 1.5 & 1.9 \\
\hline $\begin{array}{l}\mathrm{PNB} / \mathrm{PTNB}^{\mathrm{d}} \\
(70: 30)\end{array}$ & 58 & 0.36 & 0.08 & 4.5 \\
\hline $\begin{array}{l}\mathrm{PNB} / \mathrm{PTNB}^{\mathrm{d}} \\
(50 / 50)\end{array}$ & 63 & 0.38 & 0.07 & 5.4 \\
\hline $\begin{array}{l}\text { PNB/PTNB }{ }^{\mathrm{d}} \\
(30: 70)\end{array}$ & 74 & 0.40 & 0.07 & 5.7 \\
\hline PTNB $^{\mathrm{d}}$ & 95 & 0.39 & 0.06 & 6.5 \\
\hline
\end{tabular}

${ }^{\mathrm{a}}$ Determined by DSC. ${ }^{\mathrm{b}} 1$ Barrer $=10^{-10} \mathrm{~cm}^{3}(\mathrm{STP}) \mathrm{cm} /\left(\mathrm{cm}^{2}\right.$ $\mathrm{s} \mathrm{cmHg}) .{ }^{\mathrm{c}}$ From ref 5. ${ }^{\mathrm{d}}$ Measurements performed at $30^{\circ} \mathrm{C}$ and $10-100 \mathrm{mmHg}$.

tion factors is shown in Table III. $T_{\mathrm{g}}$ and permeability coefficients changed after the introduction of $30 \mathrm{~mol} \%$ TNB into copolymer with NB. More significant change in $\mathrm{PO}_{2}$ between PNB and PNB/PTNB (70/30) copolymer compared to $T_{\mathrm{g}} \mathrm{s}$ can be explained by the fact that the copolymers obtained by metathesis polymerization consist of micro blocks of monomers with different specific chain length. These micro blocks result in micro phase separation. We assume that this phenomenon more affected $\mathrm{PO}_{2}$. It is obvious that the introduction of tosylate group into the five-membered ring of the polynorbornene main chain increased the regidity of polymer chains. $T_{\mathrm{g}} \mathrm{s}$ of copolymers increased linearly with TNB content. The incorporation of TNB into polynorbornene decreased permeability with significant improvement in selectivity. A correlation exists between permeability and selectivity of gas separation. Polymers with high magnitude of permeability are usually less selective in gas separation.

Tables IV and V show that permeability coefficients and separation factors are affected by measurement temperature. The permeability coefficients increase with the temperature, but selectivity decreases. These results are not different from generally observed gas permeability of polymer membranes. Table VI presents diffusion and solubility coefficients of unsabstituted polynorbornene (PNB) and polymer with tosylate side 
Table VI. Diffusion and solubility coefficients of poly-TNB

\begin{tabular}{lcccc}
\hline \multirow{2}{*}{ Membrane } & \multicolumn{2}{c}{$\frac{D}{\mathrm{~cm}^{2} \mathrm{sec}^{-1}}$} & \multicolumn{2}{c}{$S$} \\
\cline { 2 - 5 } & \multicolumn{1}{c}{$\mathrm{O}_{2}$} & $\mathrm{~N}_{2}$ & $\mathrm{O}_{2}$ & $\mathrm{~N}_{2}$ \\
\hline PNB $^{\mathrm{a}}$ & $1.5 \times 10^{-7}$ & $0.44 \times 10^{-7}$ & $0.19 \times 10^{-2}$ & $0.33 \times 10^{-2}$ \\
PTNB & $4.04 \times 10^{-8}$ & $1.29 \times 10^{-8}$ & $0.97 \times 10^{-3}$ & $0.44 \times 10^{-3}$ \\
\hline
\end{tabular}

${ }^{\mathrm{a}}$ See ref 5.

Table V. Separation factor of copolymers at different temperature

\begin{tabular}{ccccc}
\hline & $30^{\circ} \mathrm{C}$ & $\begin{array}{c}\mathrm{O}_{2} / \mathrm{N}_{2} \\
40^{\circ} \mathrm{C}\end{array}$ & $50^{\circ} \mathrm{C}$ & $60^{\circ} \mathrm{C}$ \\
NB:NBT & & & & \\
\hline $30: 70$ & 5.8 & 5.6 & 5.9 & 4.3 \\
$50: 50$ & 5.4 & 5.5 & 5.2 & - \\
$70: 30$ & 4.4 & 4.2 & 3.6 & 2.5 \\
\hline
\end{tabular}

chain group (PTNB). To estimate the accurate D at different temperature, a series of experiments were performed. There was systematic error in the measuring of the time lag for the copolymers of TNB with NB. This method gives good results for homopolymers but fails to measure $\mathrm{D}$ and correlate $\mathrm{D}$ and $\mathrm{P}$ for the copolymers of the different composition. A possible explanation of this is the formation of micro blocks during the copolymerization of monomers. It follows from Table VI, that diffusion and solubility coefficients of nonsubstituted PNB are several times higher than those observed for PTNB. The incorporation of tosylate containing moieties into the cyclopentane ring decreased the diffusivity, solubility and $\mathrm{PO}_{2}$ of polymers. At the same time, the introduction of tosylate group (PTNB) increased the solubility selectivity $\left(\mathrm{S}_{\mathrm{O} 2} / \mathrm{S}_{\mathrm{N} 2}\right)$ from 0.58 to 2.23 and enhanced the selectivity for the gas pair $\mathrm{O}_{2} / \mathrm{N}_{2}$ from 1.9 (PNB) to 6.5 (PTNB). The selectivity observed for tosylate-containing polynorbornene is higher than that found for poly(vinyltrimethylsilane) (PVTMS), poly(trimethylsilylnorbornene) (PTMSNB) and fluorine-containing ring-opened polynorbornenes. ${ }^{4-6}$ Separation factors $\left(\alpha \mathrm{O}_{2} / \mathrm{N}_{2}\right)$ for the PVTMS and PTMSNB were 4 and 4.2 , respectively, while this factor for polynorbornene made from TNB was 6.5.

Acknowledgments. We thank CONACyT for generous support to this research with contract 25086A and NC-204. The authors thank Juan Manuel Garcia Leon,
Miguel-Angel Canseco and Ruben Gavino for their assistance in thermal, GPC and NMR-analysis.

\section{REFERENCES}

1. W. J. Koros and G. K. Fleming, J. Membr. Sci., 83, 1 (1993).

2. S. A. Stern, J. Membr. Sci., 94, 1 (1994).

3. D. R. Paul and Yu. P. Yampolskii, "Polymeric Gas Separation Membranes", CRC Press, Boca Raton, FL., 1994.

4. V. I. Bondar, Yu. M. Kukharskii, Yu. P. Yampolskii, E. Sh. Finkelshtein, and K. L. Makovetskii, J. Polym. Sci., Part B: Polym. Phys., 31, 1271 (1993).

5. Yu. P. Yampolskii, N. B. Bespalova, E. Sh. Finkelshtein, V. I. Bondar, and A. V. Popov, Macromolecules, 27, 2872 (1994).

6. Yu. P. Yampolskii, E. Sh. Finkelshtein, K. L. Makovetskii, V. I. Bondar, and V. P. Shantarovich, J. Appl. Polym. Sci., 62, 349 (1996).

7. K. D. Dorkenoo, P. H. Pfromm, and M. E. Rezac, J. Polym. Sci., Part B: Polym. Phys., 36, 797 (1998).

8. Chun-tian Zhao, M. Do Rosario Ribeiro, M. N. de Pinho, V. S. Subrahmanyan, C. L. Gil, and A. P. de Lima, Polymer, 42, 2455 (2001).

9. M. A. Tlenkopatchev, E. Miranda, M. A. Canseco, R. Gavino, and T. Ogawa, Polym. Bull., 34, 385 (1995).

10. M. A. Tlenkopatchev, S. Fomine, L. Fomina, R. Gavino, and T. Ogawa, Polym. J., 2, 622 (1997).

11. Ch. Mehler and W. Risse, Makromol. Chem., Rapid Commun., 12, 255 (1991).

12. M. A. Tlenkopatchev, S. Fomine, E. Mirando, L. Fomina, and T. Ogawa, Polym. J., 27, 1173 (1995).

13. A. Demonceau, A. F. Noels, E. Saive, and A. J. Hubert, J. Mol. Catal., 76, 123 (1992).

14. S. T. Nguyen, L. K. Johnson, and R. H. Grubbs, J. Am. Chem. Soc., 114, 3974 (1992).

15. M. A. Hillmyer, A. D. Benedicto, S. T. Nguyen, Z. Wu, and R. H. Grubbs, Macromol. Symp., 89, 411 (1995).

16. H. Katayama and F. Ozawa, Chem. Lett., 1, 67 (1998).

17. Y. Wakatsuki, H. Yamazaki, N. Kumegawa, T. Satoh, and J. Y. Satoh, J. Am. Chem. Soc., 113, 96 (1991).

18. T. A. Smith, R. P. Aplin, and P. M. Maitlis, J. Organomet. Chem., 291, C13 (1985). 